\title{
Effect of Footwear Insulation on Thermal Responses in the Cold
}

\author{
Kalev Kuklane* \\ Qiuqing Geng* \\ Ingvar Holmér \\ National Institute for Working Life, Sweden
}

\begin{abstract}
The influence of footwear insulation on foot skin temperature in the cold at low activity was investigated. Simultaneously, the thermal and pain sensations, and the influence of steel toe cap were studied. Eight participants were exposed for $85 \mathrm{~min}$ to 3 environmental temperatures $\left(+3,-12\right.$, and $\left.-25^{\circ} \mathrm{C}\right)$ wearing 5 different boots. Insulation of footwear was determined with a thermal foot model. The study showed the importance of insulation for keeping feet warm. Other factors, such as wetness and vasomotor response, however, modified the thermal response. The most affected parts were toes and heels. Cold and pain sensations were connected with considerably lower temperatures in these local points. No significant differences were observed between boots with and without steel toe cap.
\end{abstract}

cold insulation of footwear foot skin temperature thermal sensation

\section{INTRODUCTION}

Feet are easily affected by cold. They have low mass to area ratio and there are no big muscles for heat production during work. Too much insulation may cause bulky boots and may restrict walking. An increase in boot weight may increase energy costs up to $1 \%$ per $100 \mathrm{~g}$ (Jones, Knapik, Daniels, \& Toner, 1986; Legg \& Mahanty, 1986).

* Presently a doctoral student at the Division of Industrial Ergonomics, Luleå University of Technology, Sweden.

Thanks to Arbesko Gruppen $\mathrm{AB}$ and Sweden Boots $\mathrm{AB}$ for supplying the boots.

Correspondence and requests for reprints should be sent to Kalev Kuklane, National Institute for Working Life, Department of Occupational Medicine, S-171 84 Solna, Sweden. E-mail: <kkuklane@niwl.se>. 
People react to cold in different ways and individual variation in thermal response is high. During high leg activity, feet may stay comfortably warm also at low temperatures. However, when the activity is stopped, feet can quickly cool down (Oakley, 1984). At low activity or at upper body work, feet need more insulation to keep them warm. The preservation of warm feet in the cold is the result of a balance between heat input by circulatory blood and heat losses. Thus, physiological factors as well as the insulation values of footwear and socks become decisive.

The aim of this study was to determine the effects of various insulation levels on foot skin temperature changes during low activity work in cold environments. In addition, the effects of a steel toe cap were studied.

\section{METHODOLOGY}

\subsection{Instrumentation}

Experiments were made in a cold chamber adjustable from $+5^{\circ} \mathrm{C}$ to $-40^{\circ} \mathrm{C}$. The changes from set temperature were in the range of $\pm 0.8^{\circ} \mathrm{C}$ and air velocity was $0.23 \pm 0.07 \mathrm{~m} / \mathrm{s}$.

NTC-resistance, temperature matched thermistors of type ACC-001 were used for skin and chamber temperature measurements. Skin and chamber temperatures were recorded every minute.

\subsection{Boots}

Five boots were used in this study (Figure 1). They were chosen to represent three different insulation levels: a rubber boot (BS), a leather boot (A), and an insulated leather boot (W). The leather boot and the insulated leather boot were manufactured with and without steel toe cap (AS and WS, and $\mathrm{AN}$ and $\mathrm{WN}$, respectively).

\subsection{Participants and Procedure}

Eight healthy male participants with an average age of $32 \pm 6$ years $(25$ to 42 ), height of $174 \pm 5 \mathrm{~cm}$ (168 to 184 ), and weight of $75.3 \pm 8.1 \mathrm{~kg}$ (61.8 to 86.0) took part in the study. All of them agreed with the test conditions and had the possibility to quit at any time during the tests. 


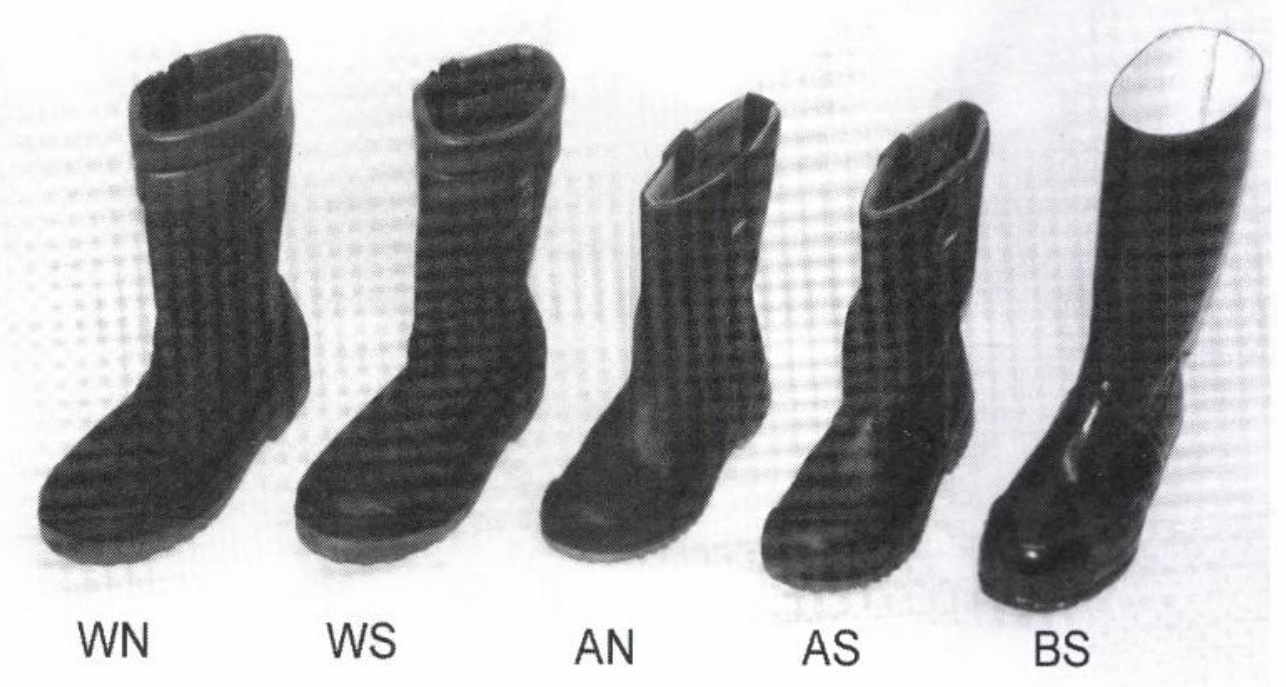

Figure 1. Boots WN and WS are heavy winter boots, AN and AS are leather boots, and $B S$ is a rubber boot. $N$ and $S$ show if the boot has a steel toe cap (S) or not $(N)$.

The tests were carried out in a climate chamber at three different environmental temperatures: $+3{ }^{\circ} \mathrm{C},-12{ }^{\circ} \mathrm{C}$, and $-25^{\circ} \mathrm{C}$. Boots WN and WS were used at the two lowest temperatures, boots BS at the two highest temperatures, boots AS in all conditions, and AN only at $-12{ }^{\circ} \mathrm{C}$. In the anteroom, the average ambient air temperature was $23^{\circ} \mathrm{C}$. The order of using the boots and environmental temperatures was mixed so that the participants had various combinations for the first and the following trials.

Each participant came 11 times: once for practice and information and 10 times for the experiment. During the information session, the participants could choose the right size of boot, their anthropometrical data were recorded, and they read the procedure protocol. The clothing was adjusted to the size of the participant and to the different environmental conditions. The insulation values of clothing were measured on a thermal mannequin according to prEN 342 (Comité Européen de Normalisation, 1995). For $+3{ }^{\circ} \mathrm{C}$, the clothing insulation was $1.95 \mathrm{clo}$, for $-12{ }^{\circ} \mathrm{C}$, it was $2.28 \mathrm{clo}$, and for $-25^{\circ} \mathrm{C}-2.55$ clo.

Skin temperature sensors were taped to the selected locations and the participant clad himself. Three thermal sensors were attached on each foot. They were placed on the dorsal foot, on the lateral heel, and on the second toe. 
The measurements started when a participant entered the climatic chamber. At once, he gave his subjective response on his thermal and pain sensations (Table 1) and later he did so after every 10 or $5 \mathrm{~min}$. The activities in the chamber are shown in Figure 2. In the $60^{\text {th }}$ min, the participant came out from the climatic chamber. The participant stayed in a warm room $\left(23^{\circ} \mathrm{C}\right)$ for $20 \mathrm{~min}$. He could open the parka and take off the gloves, but the other winter clothing had to stay on.

TABLE 1. Subjective Sensation Scales for Thermal and Pain Responses and Comfort Sensation

\begin{tabular}{|c|c|c|c|}
\hline Thermal Responses & & Pain Responses & Comfort Sensation \\
\hline 4 very hot & 0 & no pain & 1 comfortable \\
\hline 3 hot & 1 & slightly painful & 0 neutral \\
\hline 2 warm & 2 & painful & -1 uncomfortable \\
\hline 1 slightly warm & 3 & very painful & \\
\hline 0 neither warm nor cool & 4 & very, very painful & \\
\hline-1 slightly cool & & & \\
\hline$-2 \mathrm{cool}$ & & & \\
\hline-3 cold & & & \\
\hline-4 very cold & & & \\
\hline
\end{tabular}

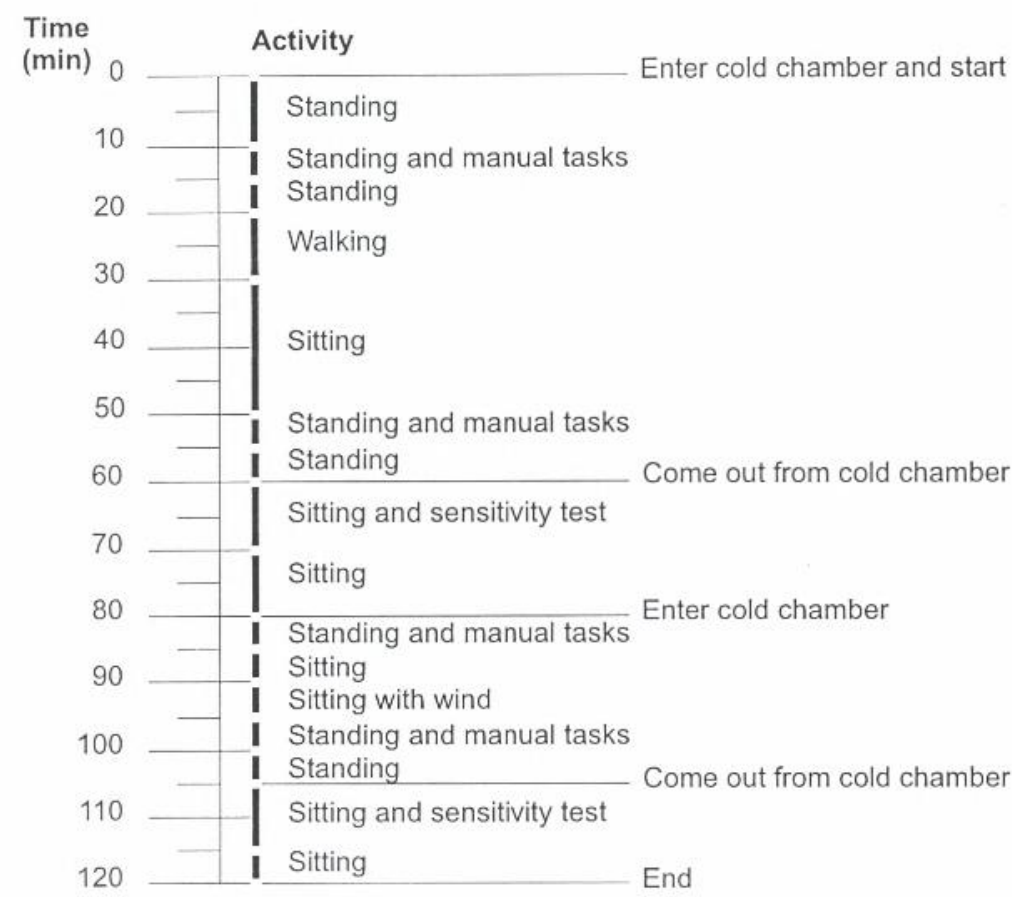

Figure 2. Time scale and test activities. 
In the $80^{\text {th }} \mathrm{min}$, the participant moved back to the cold chamber and stayed for $25 \mathrm{~min}$ (Figure 2). In the $105^{\text {th }} \mathrm{min}$, he came out from the climatic chamber. The participant sat in a warm room for $15 \mathrm{~min}$. In the $120^{\text {th }} \mathrm{min}$, the test was finished and the participant took off the clothes and the sensors were removed from the skin. The average metabolic rate during this 2-hr test was estimated to be about $80-95 \mathrm{~W} / \mathrm{m}^{2}$. The experiments were carried out during August and September.

\subsection{Insulation Measurements on Foot Model}

Measurements were carried out with a thermal foot model in a cold chamber at $+3{ }^{\circ} \mathrm{C}$ (Kuklane \& Holmér, 1998). The measured insulation values are shown in Table 2 .

TABLE 2. Insulation Values $\left(\mathrm{m}^{2}{ }^{\circ} \mathrm{C} / \mathrm{W}\right.$ ) for Various Zones and Zone Groups

\begin{tabular}{lccccc}
\hline Boot & Toes & Heel & Mid-Foot & Foot Zones & $\begin{array}{c}\text { Foot Zones } \\
\text { and Ankle }\end{array}$ \\
\hline AN & 0.237 & 0.214 & 0.224 & 0.234 & 0.233 \\
AS & 0.244 & 0.212 & 0.235 & 0.243 & 0.240 \\
BS & 0.231 & 0.188 & 0.212 & 0.217 & 0.219 \\
WN & 0.293 & 0.303 & 0.332 & 0.319 & 0.346 \\
WS & 0.289 & 0.303 & 0.326 & 0.315 & 0.342 \\
\hline
\end{tabular}

\subsection{Data Analysis}

For statistical analysis 5-min average values of skin temperatures and 5 -min differences in skin temperatures, that is, changes in skin temperature during $5 \mathrm{~min}$ were used. Analysis of variance (ANOVA) with Fisher's PLSD at .05 probability level was used. For statistical analysis of subjective responses, the same methods were used. Regression between subjective responses and foot skin temperatures was also studied.

\section{RESULTS AND DISCUSSION}

\subsection{Skin Temperature}

There was a big variability in foot skin temperatures (Figure 3). Figures 4-6 show mean foot skin temperatures and skin temperatures at each 
measured point, that is, dorsal foot, lateral heel, and second toe, at various environmental temperatures in each boot. The figures show a similar pattern of temperature change as reported by Tochihara, Ohnaka, Tuzuki, and Nagai (1995) where the effect of repeated cold exposure was studied. However, in their study (at $-25^{\circ} \mathrm{C}$ ) the participants were sitting during the entire exposure. This could explain why the drop in toe temperatures was somewhat quicker in their study. The total temperature drop of the first $60 \mathrm{~min}$ of this study and the intermittent 120-min exposures (a total of $60 \mathrm{~min}$ in the cold) of their study are quite the same, around $16-18{ }^{\circ} \mathrm{C}$, in spite of possible differences in insulation values. They did not report the insulation value of their winter boots, but only the weight $(1.56 \mathrm{~kg}$, probably per pair), which is close to the weight of WS used in this study $(1.58 \mathrm{~kg}$ per pair of size 41$)$.

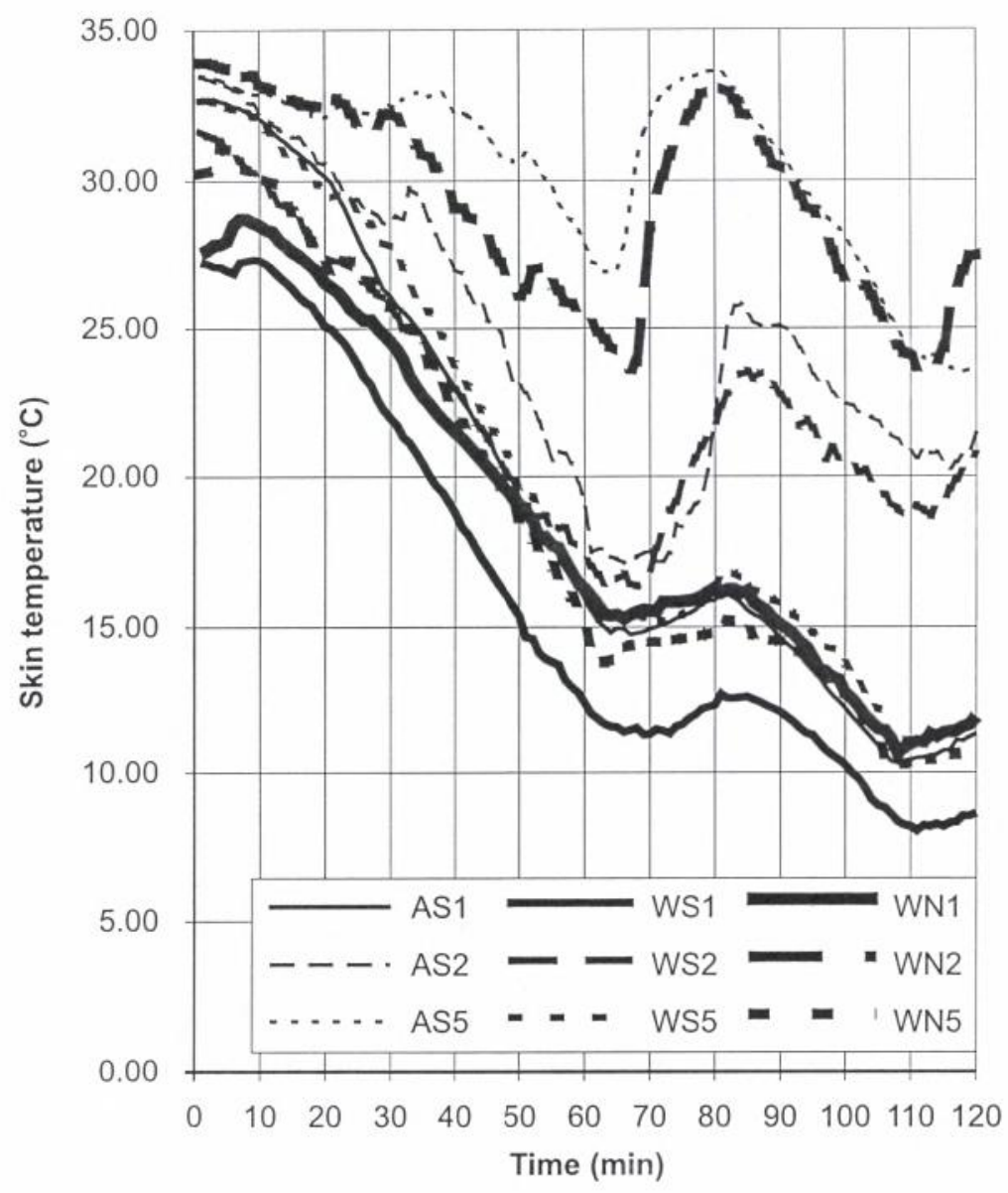

Figure 3. Mean toe skin temperatures of 3 participants at $-25^{\circ} \mathrm{C}$. 


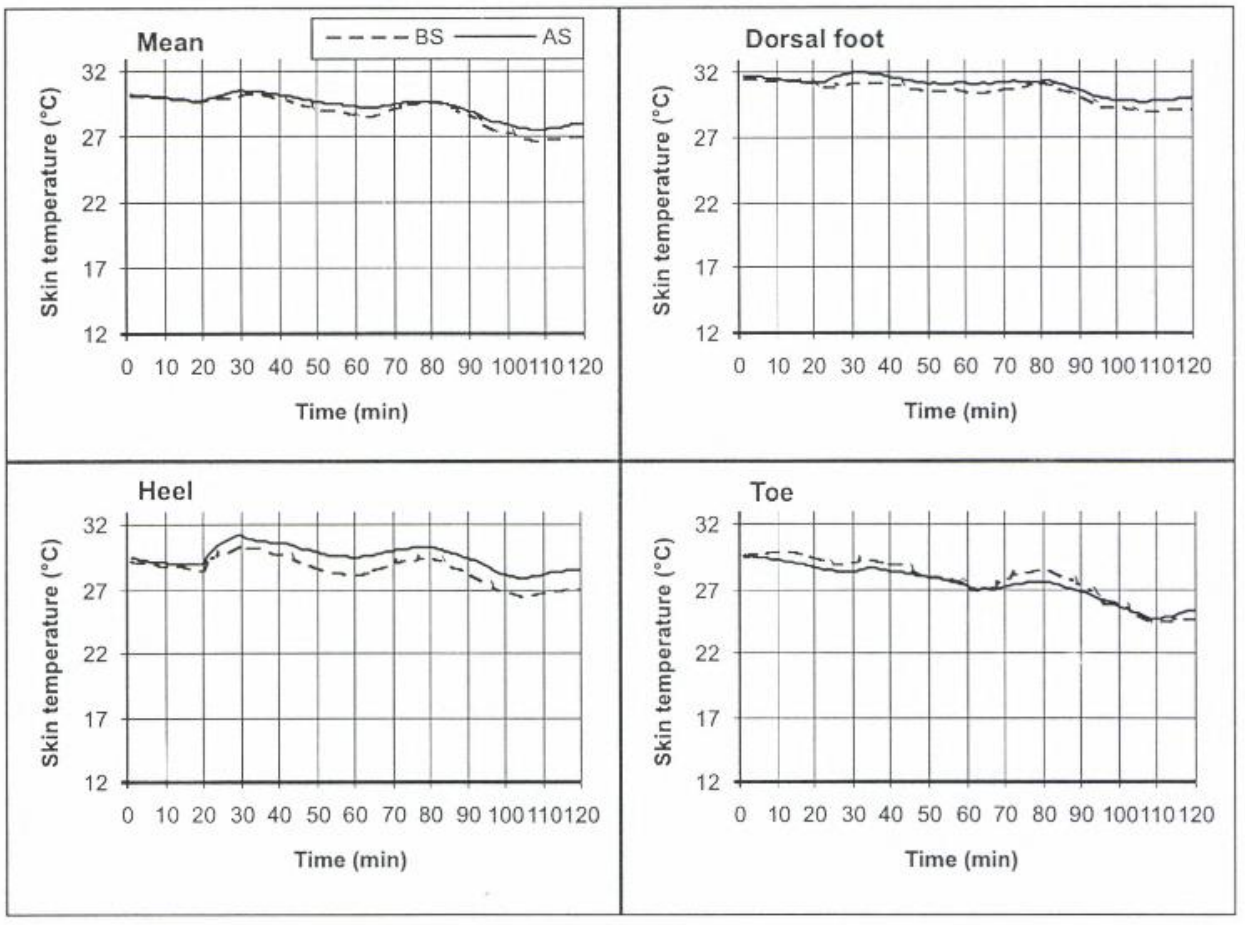

Figure 4. Foot skin temperatures at environmental temperature of $+3{ }^{\circ} \mathrm{C}$.

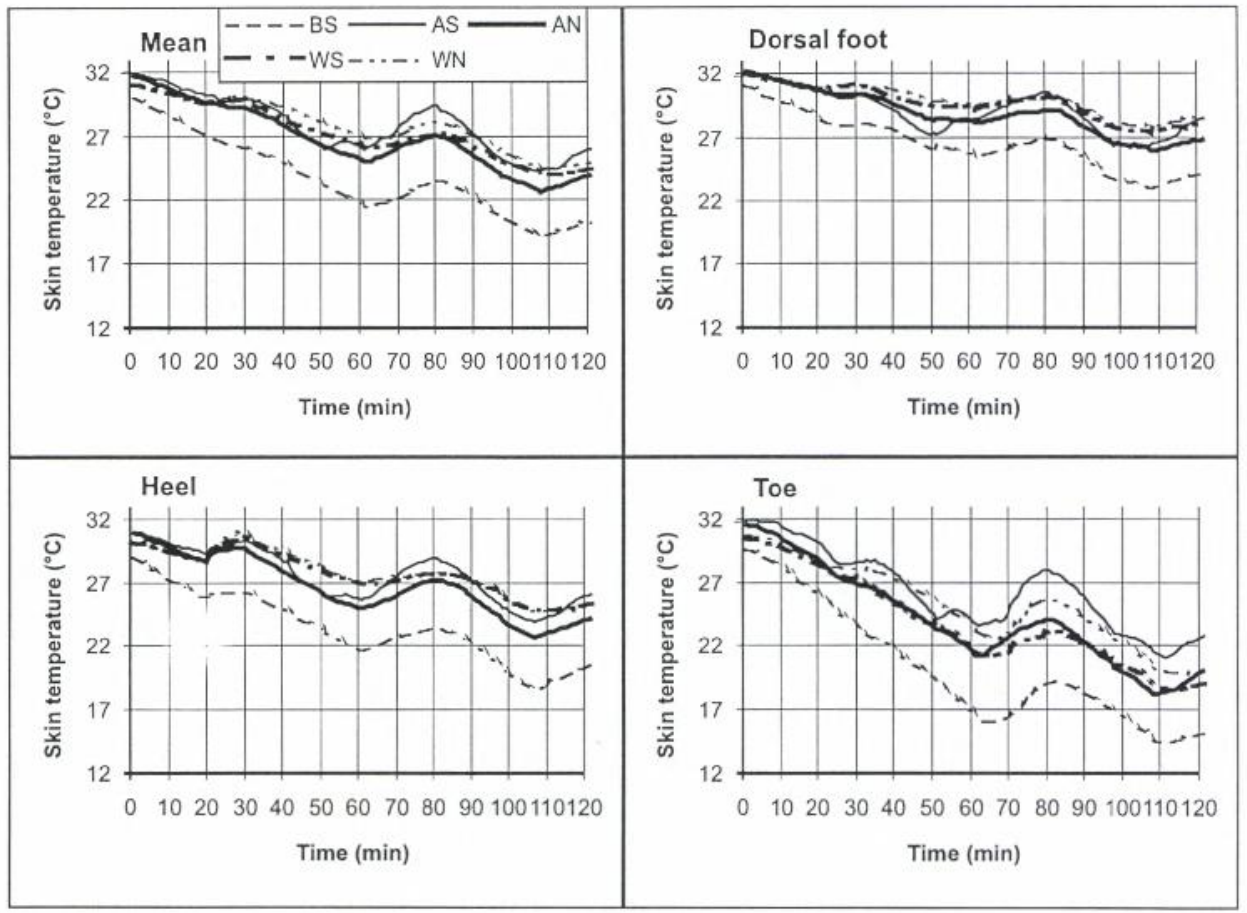

Figure 5. Foot skin temperatures at environmental temperature of $-12{ }^{\circ} \mathrm{C}$. 


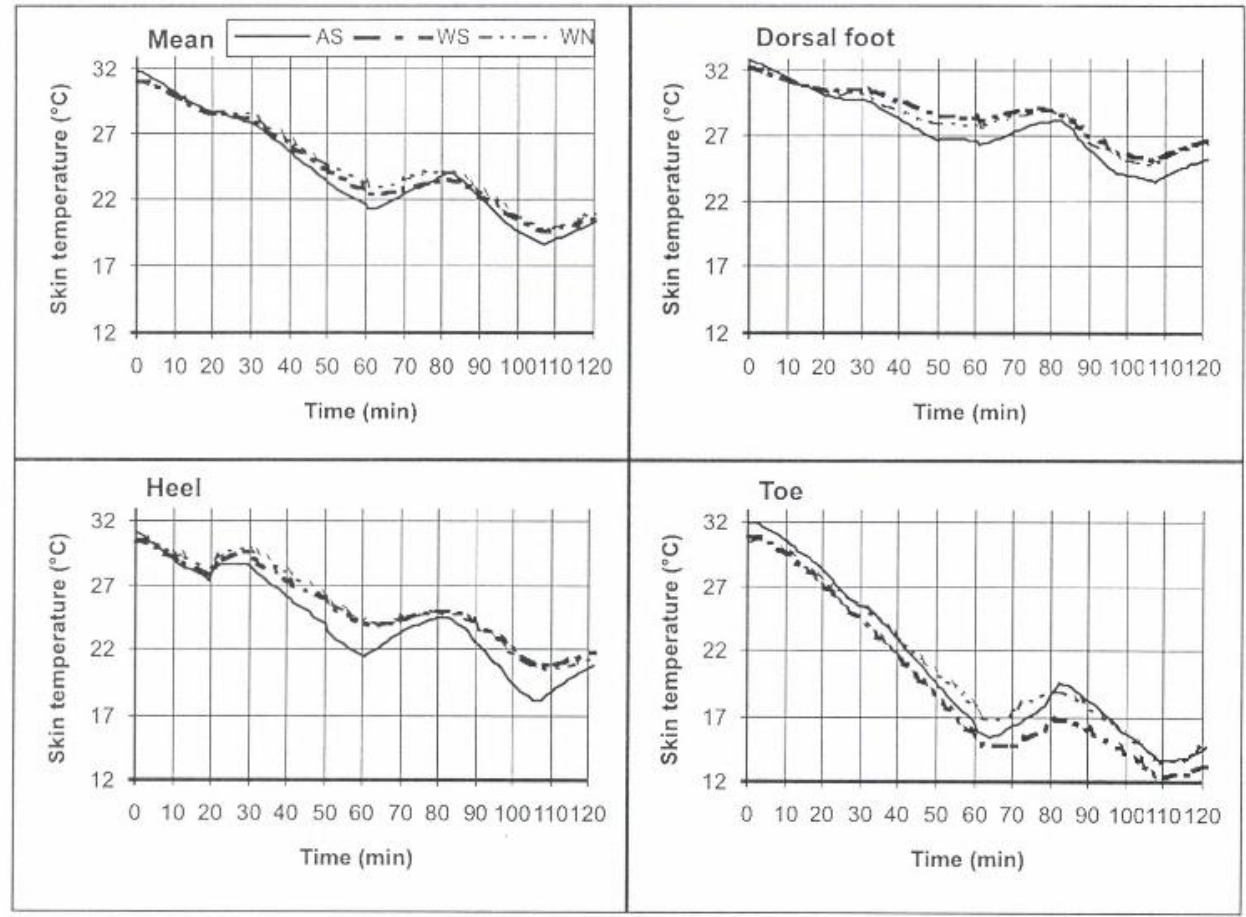

Figure 6. Foot skin temperatures at environmental temperature of $-25^{\circ} \mathrm{C}$.

At environmental temperature of $+3{ }^{\circ} \mathrm{C}$, there was no significant differences in 5-min mean values between BS and AS at any measured place or for average skin temperatures. Differences in temperature changes were also insignificant.

At $-12{ }^{\circ} \mathrm{C}$, the significant differences in 5 -min skin temperature means were present in all measured places and for average skin temperatures between BS and all other used boots. BS was significantly colder than the other boots. The biggest differences were in the heel and the smallest in the toes. The significant difference in the heel occurred already from the first 5 (AN, AS) or 10 (WN, WS) min and was present until the end of the exposure. The difference in toes was less pronounced. For $\mathrm{AN}$, it was only during $10 \mathrm{~min}(60-70)$, for $\mathrm{WN}$, it was between 20 and $75 \mathrm{~min}$, for WS, at the end of the first 30 and $60 \mathrm{~min}$, and for only AS almost constantly. The differences in toe and heel skin temperatures can be explained on the basis of the insulation values (Table 2). The highest difference in insulation levels is in the heel where BS has the lowest value, whereas toe insulation is quite high in BS, AN, and AS, and relatively low in WN and WS. In studies with a thermal foot model 
in wet conditions (Endrusick, Santee, DiRaimo, Blanchard, \& Gonzales, 1992; Kuklane \& Holmér, 1998), it was shown that when the footwear got wet, the insulation level was strongly reduced. In the latter study, the insulation of toes of WN and WS became closer to the levels of boots without an insulation layer. Slight sweating and reduction of insulation could also be an additional reason why there were less pronounced differences in the toe skin temperatures.

There were no significant differences in skin temperatures between the other boots at the environmental temperature of $-12{ }^{\circ} \mathrm{C}$. However, significant differences in temperature changes were present between all the boots at certain time intervals, that is, entering the chamber, changing the activity, and coming out from the chamber. A general tendency was that the boots with lower insulation cool quicker and warm quicker as well. Again, the differences were bigger in the heels than in the toes and the feet. The differences were generally insignificant between AS versus AN, and WS versus WN. The highest differences were between BS versus WS and WN. From the beginning of walking, the foot skin temperature increased due to the increased heat production. The rise was quicker in boots WS and WN due to their better insulation. In other boots, the foot skin temperature rise was slower and somewhat delayed. In toes, such a change was minimal and generally their temperature kept dropping. This supports the findings by Rintamäki, Hassi, Oksa, and Mäkinen (1992) that it is hard to stop a progressive temperature decrease in toes with exercise and that special attention should be paid to the cold protection of toes.

At $-25^{\circ} \mathrm{C}$, significant differences in skin temperatures between boots AS versus WS and WN occurred. The differences were present from 45 to $60 \mathrm{~min}$ in the heels and the feet, and 95 to $110 \mathrm{~min}$ in the heels. Temperatures were higher in boots with higher insulation. In the toe and for ayerage skin temperature, the differences were insignificant. In the temperature change, significant differences were present at activity and environment change and more so in the heels. The changes were quicker for AS.

The most significant differences between the boots were found in the heels, probably due to the fact that the insulation difference in that zone was the biggest. Although the heel zone insulation was the lowest for boots AS, AN, and BS, the heel temperature was kept higher than the toe temperature. Only at the start of the exposure, the heel temperature could be lower than the toe temperature. Also, the warming effect of 
activity was highest in the heels. This could be related to the fact that the heel is more central to circulation than the toes and not so physically protruding as the toes.

Skin temperatures in the same boots at different environmental temperature differed significantly. However, the differences started at different time points. For BS, significant differences started from the $10^{\text {th }} \mathrm{min}$ in the feet and by the $20^{\text {th }} \mathrm{min}$ also in the toes, for AS, at around the $30^{\text {th }} \mathrm{min}$, and for WS and $\mathrm{WN}$ in the $35^{\text {th }} \mathrm{min}$. It can be easily understood that the boots with higher insulation are less affected by environmental temperature than boots with lower insulation.

The results of this study point to some interesting tendencies. It seems that the differences in the insulation of footwear begin to influence feet temperatures only from certain environmental temperature. For example, BS and AS showed minimal differences at $+3{ }^{\circ} \mathrm{C}$, but at $-12{ }^{\circ} \mathrm{C}$ the difference was substantial. At the same time, the skin temperatures of AS and AN did not differ significantly from WS and WN at $-12{ }^{\circ} \mathrm{C}$, whereas at $-25^{\circ} \mathrm{C}$ the differences were noted. During longer exposures at the same low activity level, probably the differences should appear little by little as feet temperatures keep dropping in all types of boots. Similarly, at a higher activity level, the differences should appear quicker because insulated boots preserve the heat better. Considering the fact that in wet boots the toe insulation of WS and WN is lowered and did not considerably differ from the other boots (Kuklane \& Holmér, 1998), the toe skin temperature should drop similarly and be the limiting factor for exposure time.

The differences could also be related to boot material. The evaporation resistance seems to have great influence. BS had only a slightly lower insulation, but the higher evaporative resistance increased moisture absorption (Kuklane \& Holmér, 1998) making it significantly colder at low environmental temperatures.

At higher environmental temperatures, the temperature drop in the feet is strongly connected with harsh conditions such as wet boots, restriction of blood flow to the feet, and wearing the boots for many days without taking them off (Oakley, 1984). In these conditions, the initial insulation of boots has lesser effect and the main factor is to keep feet dry. The possibility to allow the feet to "breathe" could be important. A somewhat similar conclusion can be drawn from the results of this study at lower temperatures. 


\subsection{Subjective Responses}

The thermal and pain sensation responses are shown in Figure 7. Linear regression fitted the thermal sensation quite well (Figure 8). However, for the pain sensation, a polynomial regression fitted better (Figure 9): for linear regression $R^{2}=.288$, whereas for polynomial $R^{2}=.412$. Whereas the thermal sensation correlated best with mean foot skin temperature, the pain sensation had best correlation with toe temperatures $\left(R^{2}=.433\right.$,

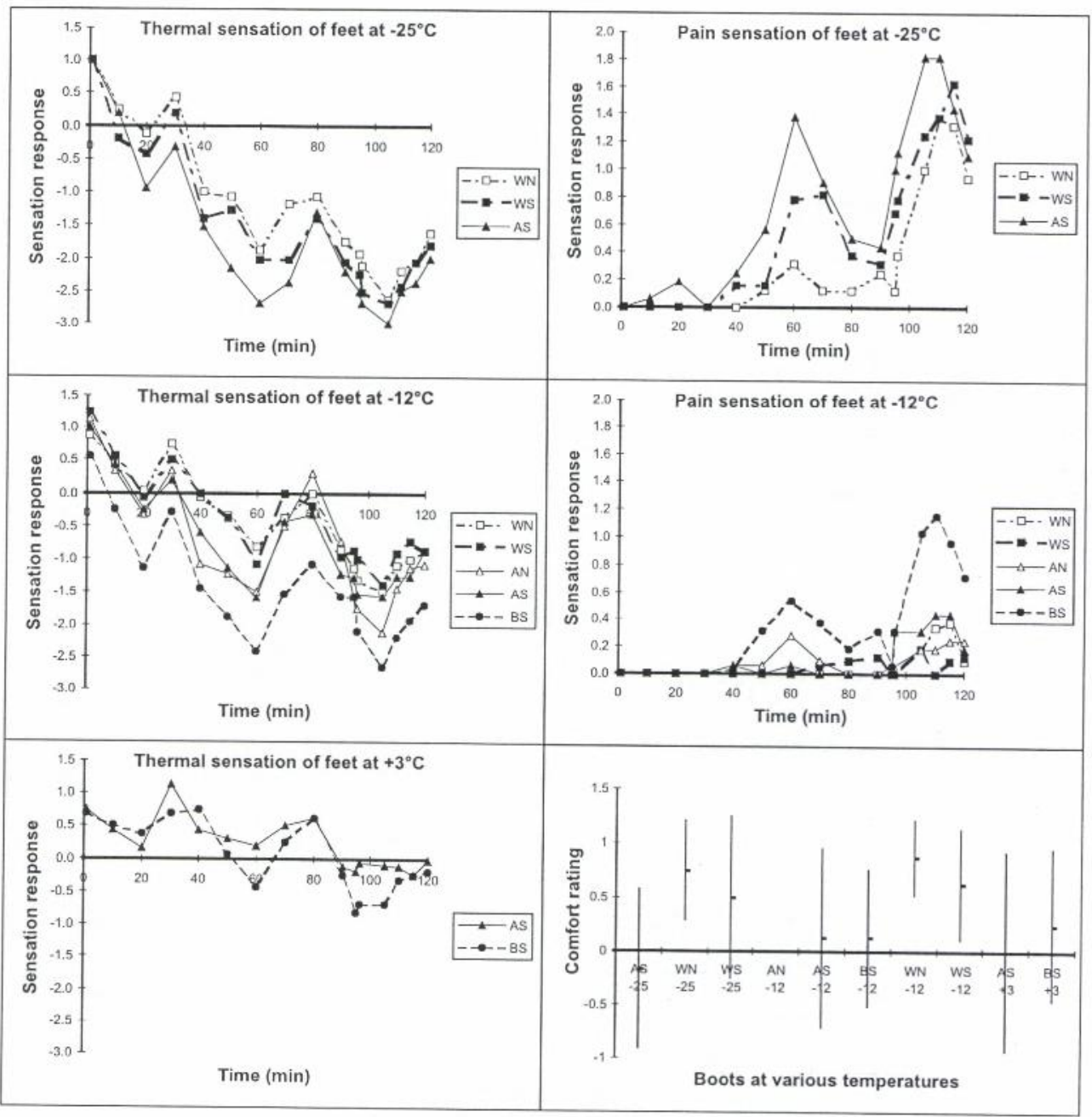

Figure 7. Thermal (rating scale from -4 to +4 ) and pain (rating scale from 0 to 4) sensations, and general (wearing) comfort (rating 1,0 , and -1 ) responses. At $+3^{\circ} \mathrm{C}$ there was no pain. 


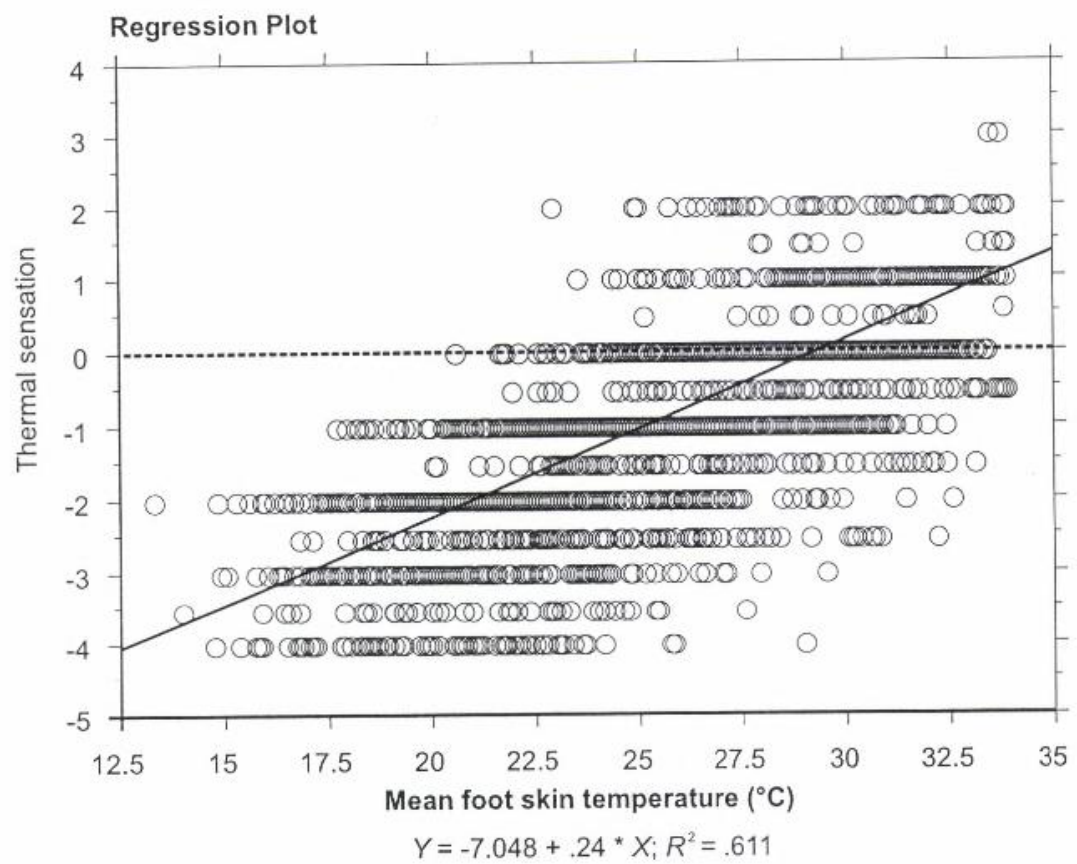

Figure 8. Thermal sensation versus mean foot skin temperature. Data on all participants in various conditions.

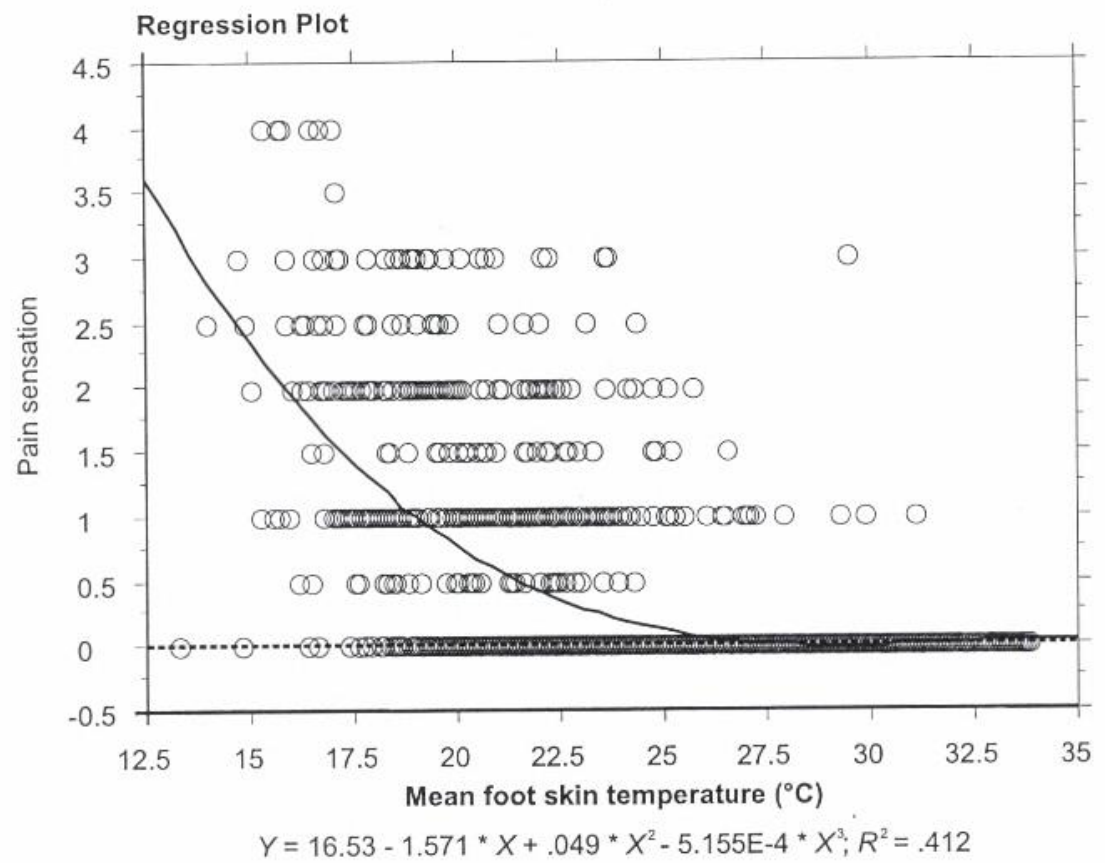

Figure 9. Pain sensation versus mean foot skin temperature. Data on all participants in various conditions. 
polynomial). Generally, the subjective responses followed skin temperatures.

Statistical analysis of the thermal and pain sensations showed few significant differences between boots at various temperatures. At $+3{ }^{\circ} \mathrm{C}$ of ambient temperature, there was no significant differences in the thermal sensation and no pain sensation at all. At $-25^{\circ} \mathrm{C}$, the significant differences were present between WN and AS in both thermal and pain sensations for short periods (2-3 times) over the 120-min test: AS was perceived as colder. At $-12{ }^{\circ} \mathrm{C}$, the differences were generally present between WS and WN, and BS. BS (rubber boot) was perceived to be significantly colder in time intervals 20 to $70 \mathrm{~min}$ and around the $110^{\text {th }}$ min. There were no significant differences at this temperature between other boots, except in the $40^{\text {th }}$ min between AS and BS, AN and WN, $\mathrm{AN}$ and WS, and in the $80^{\text {th }}$ min between AN and BS. WN and WS were perceived to be the warmest and $\mathrm{BS}$ the coldest. In the pain sensation, significant differences at $-12{ }^{\circ} \mathrm{C}$ were present at the end of cold exposures and the start of warm breaks between BS and other boots. Pain in the feet was greater in BS than in other types of boots.

Thermal regression agrees with previous observations by Enander, Ljungberg, and Holmér (1979) and Luczak (1991) that the feet generally start feeling cold at around $25^{\circ} \mathrm{C}$ and when feet skin temperatures drop under $20^{\circ} \mathrm{C}$, a strong perception of cold occurs. Still, the distribution was very wide. Whereas the responses of some participants at mean foot skin temperature of $20-25^{\circ} \mathrm{C}$ were still neutral (0) or even slightly warm (1), the responses of the other participants indicated already very cold feet $(-4)$. However, when the feet got used to the cold or the skin temperature rose slightly, the subjective responses became closer to neutral or showed warm responses. Other reasons for such a wide distribution can be individual differences in thermal sensitivity, perception, and preferences. Similar differences were found in the whole body thermal sensation. Even the same participant in similar conditions, for example, WS and WN at $-25^{\circ} \mathrm{C}$, could show considerable differences in the thermal sensation, indicating variation in the whole-body heat balance rather than feet temperature.

It seems that for a stable cold sensation, a certain negative change in skin temperature is needed. Tanaka et al. (1985) showed that cold and pain sensations during immersion of the feet in cold water were the strongest during the $2^{\text {nd }} \mathrm{min}$ of exposure when the continuous temperature change was the quickest. Later on, the temperature drop slowed 
down, and the pain and cold sensations were reduced. In a study by Tochihara et al. (1995), a similar trend was noted. During shorter exposures, the rate of the skin temperature drop was the same as during longer exposures. However, the continuous reduction of skin temperatures was shorter in shorter exposures. In general, it took a longer time with short exposures to reach the same skin temperature than with long exposures. There was lower pain and cold sensation during short exposures, although final lowest skin temperatures were about the same. A similar effect seemed to be present in this study. Although skin temperatures in various boots were at about the same level, the cold and pain sensations in the boots with lower insulation were higher probably due to the fact that the temperature drop in these boots was more rapid.

Slight pain could occur when feet temperatures are around $20-23^{\circ} \mathrm{C}$, and at temperatures under $20^{\circ} \mathrm{C}$ pain quickly grew. However, when the feet warmed up again, a pain sensation could be present due to vasodilatation and increased blood flow to the feet (strong and quick warm sensation).

The correlation was strongest between subjective responses and mean foot skin temperature. However, the cold or pain sensation was often connected with a particular foot part: the heel for some participants, but the toes for most of them. This agrees with the conclusions of Rintamäki and Hassi (1989) on subjective response dependence on the lowest temperature in the feet. The toe skin temperature was considerably lower than the mean foot skin temperature when participants gave their cold and pain response. Toes started to feel cold at around $20^{\circ} \mathrm{C}$ and a strong perception of cold occurred between 10 and $15^{\circ} \mathrm{C}$. Pain occurred around $15^{\circ} \mathrm{C}$ and grew quickly with a decrease in the toe temperature. A drop of the toe skin temperature below $10^{\circ} \mathrm{C}$ was connected with very strong pain.

No significant differences were observed between boots with and without steel toe cap. For boots with lower insulation (AS and AN), the toe skin temperature (Figure 5) was generally lower in boots without steel toe. At the same time, for boots with higher insulation (WS and WN) there was an opposite tendency (Figures 5 and 6). It could be possible that at a low insulation level, steel toe has a more important role as an additional insulation layer, whereas this effect becomes negligible at higher insulation levels and some other factors have greater influence, for example, mass (heat content), water barrier, and so forth. Regarding thermal sensations (Figure 7), there was a similar tendency. 
AN showed just somewhat quicker warm-ups than AS. At the end of the second cold exposure and the beginning of warm-up, the pain sensation in AS was greater than in $\mathrm{AN}$. At $-12^{\circ} \mathrm{C}$, there were hardly any differences in pain and thermal responses for boots WS and WN, whereas at $-25^{\circ} \mathrm{C}$, the feet in WN seemed to have a somewhat lower cold sensation and less pain. However, these differences were insignificant and at present it is hard to say what could cause that tendency.

According to Bergquist and Abeysekera (1994), for safety shoes in the cold climate the fit is ranked first by users and manufacturers, and second by experts, whereas thermal comfort is ranked first by experts and second by users and manufacturers. After each trial, the participants were asked about the general comfort of the boots. Boot WN got the highest rating and AS the lowest one (Figure 8). It can be assumed that thermal comfort has an influence on the subjective ratings of general comfort of the footwear. Still, the comfort rating for the coldest boot (BS) was higher than that for AS and AN. The low values for AS could be connected with the poor fit of the boot. The heel of some participants moved up and down in the boot, whereas other participants complained about pain from the pressure onto the lateral heel (between the heel and ankle bone).

\section{CONCLUSIONS}

1. There are considerable individual differences in physiological responses to the cold exposure.

2. Initial (basic) footwear insulation is an important factor in keeping feet warm, however, the activity of the participants and the dryness of footwear influence strongly foot temperatures, too.

3. Insulation gained importance at lower environmental temperatures and with activity. The latter effect is due to the fact that generated heat is better trapped in boots with higher insulation.

4. The most affected parts are the heels and the toes. The results from thermal foot measurements point to insufficient insulation in toe parts.

5. No significant differences between boots with and without steel toe cap were observed.

6. The thermal sensation in the feet was relatively well correlated with mean foot skin temperature, in spite of considerable individual variation. 
7. The cold and pain sensations were connected with locally lowered foot skin temperature, especially in the toes.

\section{REFERENCES}

Bergquist, K., \& Abeysekera, J. (1994). Ergonomics aspects of safety shoes worn in the cold climate. In Proceedings of the 3rd Pan-Pacific Conference on Occupational Ergonomics, Seoul, Korea (pp. 590-594). Seoul, Korea: Ergonomic Society of Korea.

Comité Européen de Normalisation. (1995). Protective clothing. Ensembles for protection against cold (Standard No. prEN 342:1995). Brussels, Belgium: Author.

Enander, A., Ljungberg, A.-S., \& Holmér, I. (1979). Effects of work in cold stores on man. Scandinavian Journal of Work, Environment and Health, 5, 195-204.

Endrusick, T.L., Santee, W.R., DiRaimo, D.A., Blanchard, L.A. \& Gonzales, R.R. (1992). Physiological responses while wearing protective footwear in a cold-wet environment. In J. McBriarty \& N. Henry (Eds.), Performance of Protective Clothing: Fourth volume (STP 1133, pp. 544-556). Philadelphia: American Society of Testing and Materials.

Jones, B.H., Knapik, J.J., Daniels, W.L., \& Toner, M.M. (1986). The energy cost of women walking and running in shoes and boots. Ergonomics, 29(3), 439-443.

Kuklane, K., \& Holmér, I. (1998). Effect of sweating on insulation of footwear. International Journal of Occupational Safety and Ergonomics, 4(2), 123-136.

Legg, S.J., \& Mahanty A. (1986). The energy cost of backpacking in heavy boots. Ergonomics, 29(3), 433-438.

Luczak, H. (1991). Work under extreme conditions. Ergonomics, 34(6), 687-720.

Oakley, E.H.N. (1984). The design and function of military footwear: A review following experiences in the South Atlantic. Ergonomics, 27(6), 631-637.

Rintamäki, H., \& Hassi, J., (1989). Foot temperature and thermal sensations in the foot in the naked and clothed man. In J.B. Mercer (Ed.), Thermal physiology (pp. 173-176). Amsterdam: Elsevier.

Rintamäki, H., Hassi, J., Oksa, J., \& Mäkinen, T. (1992). Rewarming of feet by lower and upper body exercise. European Journal of Applied Physiology, 65, 427-432.

Tanaka, M., Yamazaki, S., Ohnaka, T., Harimura, Y., Tochihara, Y., Matsui, J., \& Yoshida, K. (1985). Effects of feet cooling on pain sensation and cardiovascular responses. Journal of Sports Medicine and Physical Fitness, 25(1-2), 32-39.

Tochihara, Y., Ohnaka, T., Tuzuki, K., \& Nagai, Y. (1995). Effects of repeated exposures to severely cold environments on thermal responses of humans. Ergonomics, 38(5), 987-995. 